\title{
Expressando a fé: experiência religiosa, testemunho autobiográfico e religioso na poesia de Adélia Prado
}

\author{
Douglas Rodrigues da Conceição ${ }^{1}$
}

\begin{abstract}
Resumo: Vem da própria Constituição Pastoral Gaudium et Spes uma preocupação que gravita em torno da relação existente entre "cultura humana e a formação cristã." O texto conciliar sobressalta que determinadas expressões culturais, tais como "a literatura e as artes", "são de grande importância para a vida da Igreja", mas também reconhece que a relação entre a própria cultura humana e a tradição religiosa cristã católica nem sempre se dá modo harmônico e, portanto, se cosntitui num desafio ao fazer teológico da Igreja. Se entrevê, portanto, a grande responsabilidade das artes, pois são nelas, de modo mais nítido, que a autoexpressividade do ser humano assume uma forma, sobretudo, quando nelas o próprio homem retrata a busca por uma compreensão de si mesmo e a busca por respostas aos seus mais profundos dilemas. Reconhecendo a possibilidade de superação das fendas que separam a cultura humana da cultura propagada pela tradição cristã, procuraremos demonstrar, nesta comunicação, que a experiência religiosa entrevista na literatura da poetisa católica Adélia Prado, evocada por um eu-poético emergente nos versos de sua poesia, se perfaz a partir de uma dinâmica de reconhecimento e de distanciamento, portanto ambígua, da confissão religiosa da prórpria escritora mineira. Dois eixos, portanto, serão explorados mais detidamente nesta comunicação: 1. A clara influência de uma tradição religiosa no seu fazer literário e daí depreender o potencial teológico deste fazer; 2. Problematizar a presença de um nítido pacto autobiográfico travado entre o eu-poético feminino da poesia adeliana e o próprio testemunho biográfico-religioso da escritora.
\end{abstract}

Palavras-chave: Literatura. Testemunho autobiográfico. Experiência religiosa.

\section{A religião, a literatura e as artes}

Comecemos pelo problema de fundo ao qual me impus: inquietado por uma questão exposta na constituição pastoral Gaudium et Spes, ocupei-me em perguntar sobre a possível suspensão da fenda existente entre cultura humana e cultura cristã, a partir de um importante eixo da cultura, a saber, a literatura. Outra interrogação, aquela que se importa com as formas de transparecimento das experiências de natureza religiosa, na contemporaneidade, momento em que a própria religião é percebida, por um lado, a partir de um intenso refluxo e, por outro, a partir de seu esfacelamento, pode ter, na literatura de escritores e poetas, múltiplos esclarecimentos. Se a separação entre cultura humana e cultura cristã, por exemplo, fosse de fato uma realidade estanque, como poderíamos, portanto, explicar a presença de um notável

\footnotetext{
${ }^{1}$ Douglas Rodrigues da Conceição é Doutor em Ciências da Religião e professor Adjunto II da Universidade do Estado do Pará, onde atua como docente junto ao Programa de Pós-graduação em Ciências da Religião. Atualmente, pesquisa literatura brasileira a partir da interface religião e literatura. E-mail: abismos@gmail.com.
} 
testemunho religioso e de fé no âmbito de tantos textos literários? Cabe, então, a pergunta sobre o sentido e presença dessas formas testemunhais em grande parte de nossa literatura. Talvez seja essa a preocupação exposta pela Gaudium et Spes, Parte II , Capítulo II, na Seção 3, ao entender que, embora a igreja tenha contribuído "para o progresso cultural, mostra, contudo, a experiência que, devido a causas contingentes, a harmonia da cultura com a doutrina cristã nem sempre se realiza sem dificuldades" (DOCUMENTOS DO CONCÍLIO ECUMÊNICO VATICANO II, 1997, p. 617). Tais dificuldades, contudo, afirma o texto da constituição pastoral, "não são necessariamente danosas para a vida da fé; antes podem levar o espírito a uma compreensão mais exata e mais profunda da mesma fé" (DOCUMENTOS DO CONCÍLIO ECUMÊNICO VATICANO II, 1997, p. 617). Assim, afirma a Gaudium et Spes:

[...] a literatura e a arte são também, segundo a maneira que lhes é própria, de grande importância para a vida da igreja. Procuram elas dar expressão à natureza do homem, aos seus problemas e à experiência das suas tentativas para conhecer-se e aperfeiçoar-se a si mesmo e ao mundo; e tentam identificar a sua situação na história e no universo, dar a conhecer as suas misérias, e alegrias, necessidades e energias, e desvendar um futuro melhor. Conseguem assim elevar a vida humana, que se expressa de formas diferentes, segundo os tempos e lugares. Por conseguinte, deve trabalhar-se por que os artistas se sintam compreendidos, na sua atividade, pela Igreja e que, gozando duma conveniente liberdade, tenham mais facilidade de contatos com a comunidade cristã. A Igreja deve também reconhecer as novas formas artísticas, que segundo o gênio próprio das várias nações e regiões se adaptam às exigências dos nossos contemporâneos. Serão admitidos nos templos quando, graças a uma linguagem conveniente e conforme com as exigências litúrgicas, elevam o espírito a Deus. Deste modo, o conhecimento de Deus é mais perfeitamente manifestado; a pregação evangélica torna-se mais compreensível ao espírito dos homens e aparece como que integrada nas suas condições normais de vida (DOCUMENTOS DO CONCÍLIO ECUMÊNICO VATICANO II, 1997, p. 617-618).

Neste ensaio, a minha ocupação principal recairá sobre a literatura da poetisa mineira e católica confessa Adélia Prado. A partir do anúncio da fé que a poetisa mineira deixa transparecer em seu testamento poético é que me ocuparei de sua literatura enquanto literatura de testemunho. Dois eixos serão mais detidamente explorados nesta comunicação: 1 . Problematizar a presença de um nítido pacto autobiográfico travado entre o eu-poético feminino da poesia adeliana e o próprio testemunho biográfico-religioso da escritora. 2. A clara influência de uma tradição religiosa no seu fazer literário. 


\section{A literatura como testemunho da fé}

Os estudos sobre a chamada literatura de testemunho estão em linha ascendente. É o segundo pós-guerra o marco impulsionador deste tipo de literatura. O cânone que performa esta nova estética literária é prioritariamente oriundo dos textos que os pesquisadores chamam de Shoah ou catástrofe (Cf. SELIGMANN-SILVA, 2003). Nestrovski e Seligmann-Silva reconhecem como lícita a expansão das leituras extraídas do Shoah para aplicá-las à leitura da nossa realidade como um todo (Cf. NESTROVSKI; SELIGMANN-SILVA, 2000, p. 10). Se me for permitida uma definição do que pretendo chamar de literatura de testemunho, diria, pois, que toda literatura de testemunho é aquela insuflada por uma experiência radical, limite e extraordinária por parte daquele que decide testemunhar tal experiência. É nesse caminho que posso correlacionar o tipo de experiência que é produzido no âmbito da religião e a que é representada no campo da literatura de testemunho. No dizer de Paul Tillich, é na religião que experimentamos o incondiconado; é no seu interior que a fé se apresenta como o estado em que se é possuído por algo que nos toca incondicionalmente. E é a divindade na ideia de Deus que representa esse elemento incondicional, aquilo que se torna preocupação última para o homem (TILLICH, 2001, p. 7-11). As experiências de profundidade estão fortemente presentes nas tradições religiosas. São essas experiências que sinalizam o estar diante do incondicional; "se trata daquilo que o homem experimentou como incondicional, de validade última" (TILLICH, 2001, p. 11). A profundidade que a experiência com o sagrado alcança, em nível radical, quase sempre - e eu diria sempre - deixa os rastros da religião enraízados e praticamente irremovíveis em algum lugar. Este lugar, privilegiadamente, é ocupado pela memória. Representar ou não representar - e aqui entra ou não a literatura de testemunho não altera, afinal, a consciência do que precisa ser dito (Cf. NESTROVSKI; SELIGMANNSILVA, 2000, p. 11). Os rastros da experiência profunda permanecem em algum lugar, se representados ou não.

É a sobrevivência de uma experiência radical que a chamada literatura de testemunho, pelo menos no modo como a pretendo abordar, expõe. Afirma Seligmann-Silva que a literatura de testemunho expressa o seu teor testemunhal de modo mais evidente ao tratar de eventos-limite, de situações que 'marcam' e 'deformam', tanto a nossa percepção como também a nossa capacidade de expressão (Cf. SELIGMANN-SILVA, 2003, p. 8). Talvez seja este o sentido das experiências com Deus, experiências pungentes, que sobreviveram e que sobrevivem na expressão das testemunhas dessas experiências em todas as épocas. Uma afirmação, portanto, pode ser anunciada: ninguém sai ileso depois de ter uma experiência com 
Deus. Quem testemunha sua própria experiência profunda, ou seja, quem ultrapassa o limite do silêncio em favor de um autotestemunho "desfaz os lacres da linguagem que tentam encobrir o indizível que a sustenta" (SELIGMANN-SILVA, 2003, p. 48).

É essa a posição que eu admito para esta literatura. É a luta contra o esquecimento de um evento profundo que traz a lembrança de uma experiência excepcional à superfície da literatura de testemunho. A arte da memória e a literatura de testemunho são, no dizer de Seligmann-Silva, uma expressão de cicatrizes (Cf. SELIGMANN-SILVA, 2003, p. 56). São estas cicatrizes, por meio do testemunho da experiência religiosa, que o eu-poético adeliano busca textualmente representar, em certa medida. Portanto, a discursividade (o evento discursivo) fundada pela literatura do $e u$ de uma testemunha quer, em última instância, trazer à superfície do discurso do texto uma experiência radical e profunda (positiva ou negativa).

Contraditando Kuschel, em sua obra Os escritores e as escrituras, nem todo discurso sobre Deus, no âmbito da literatura contemporânea, vem expressar uma crise espiritual da consciência moderna (KUSCHEL, 1999, p. 217). Ao contrário: a alteridade que a literatura requer, e aqui em especial a que denomino de literatura de testemunho, é a de ter o seu falar sobre Deus e sobre os temas da fé cristã não apenas como discurso ficcional ou poético, diminuídos sensivelmente em seus campos de significado, mas como testemunho crível e autêntico de uma experiência profunda com Ele. Creio que a posição destacada pela Gaudium et Spes, em direção ao reconhecimento do trabalho feito por escritores e poetas, espelha melhor o que desejamos realizar no horizonte da literatura adeliana.

Rompe-se, portanto, com o dogma do ateísmo enquanto a priori do fazer literário. $\mathrm{O}$ julgamento estético de um conjunto literário, aquele modula a oposição entre a boa e a má literatura, não deve recair sobre as convicções do/a escritor/a (quaisquer que sejam elas), nem tampouco sobre os temas por ele/a retratados. Demonstra-se, assim, em Adélia Prado, que Deus nem sempre será um péssimo princípio estético. Talvez seja esse o problema que subliminarmente a Gaudium et Spes expõe, ao afirmar a necessidade de dar a devida audição aos poetas e aos escritores. Os versos de Adélia Prado admitem, sem dúvida, uma interpretação do modo com o qual ela recepcionou aquilo que recebeu e experimentou no campo da fé.

\section{Por um pacto entre escrita e autoria}

A existência de um elo entre determinadas expressões da poesia de Adélia Prado e a perspectiva autoral, circunstanciada pela voz em primeira pessoa, deve manter-se na rota de 
um pacto autobiográfico ou, do contrário, compromete-se o testemunho de fé em sua literatura. Essa questão não é tão simples o quanto parece. Se a chamada literatura de testemunho emerge das experiências profundas e se o horizonte autoral (testemunhal) não for preservado, tal expressão literária alcançaria apenas um grau de inventividade e/ou de ficcionalidade e não propriamente aquilo que com o texto adeliano pretendo atingir; ou seja: um testemunho de fé tecido na e pela poesia. Consideremos, pois, um problema que fora muito bem levantando tanto por Michel Foucault (2006), quanto por Roland Barthes (2004), que é o problema da chamada morte do autor. Portanto, a defesa de um pacto autobiográfico, no horizonte da literatura de Adélia Prado, é necessária por dois motivos: 1. Sob uma perspectiva de gênero, a voz da poesia adeliana não é neutra. É o feminino que demarca o lugar do eu; 2. Sob o ponto de vista da expressividade temática, é a religião que ocupa certa centralidade. Isto quer dizer que, no percurso que procuro traçar, a presença de um eu feminino e a de temas religiosos destinam-se a um processo de singularização de uma identidade que testemunha uma experiência profunda, não apenas pela obrigação de uma confissão, mas em razão da ruptura do seu silêncio. ${ }^{2}$

Se o meu ponto de partida é a afirmação do reconhecimento de uma escritura que deixa transparecer a sua autoria, a partir da poética de Adélia Prado, cabe-me, agora, dizer que este processo se dá sob o prisma de um possível pacto autobiográfico, travado entre o eu-autor de Adélia e o eu-poético, que se revela em grande parte de sua poesia, enquanto presentificação de um si que se afirma. Se para Foucault e Barthes torna-se imprescindível a morte do autor para que se perceba a sua real função (ideológica) nos enunciados discursivos, em Adélia há o oposto, pois a emergência de um eu-autor, presente nos rastros e nos vestígios biográficos e autobiográficos deixados em sua poesia, não só autentica uma voz feminina, que quer se autoafirmar, mas também revela um processo de reconhecimento de um eu marcado pela recuperação de uma memória religiosa. ${ }^{3}$ Escrever ou reescrever e testemunhar a própria experiência, a experiência de um $e u$, é a condição que impede o sepultamento da lembrança de si e de uma identidade que insiste em se afirmar. Escrever, reescrever e testemunhar

\footnotetext{
2 A tradição cristã, mesmo depois dos efeitos da secularização, continuou permeável às confissões. A autobiografia presente nos textos literários pode ter recebido grande influência desse aspecto da cultura cristã (Cf. ROCHA, 1992, p. 15).

${ }^{3}$ Essa memória religiosa no horizonte adeliano teria, em tese, o papel de presentificar, nos escombros da lembrança, sua experiência religiosa que remonta à infância. Chris Marker apresenta, em SEM sol, uma questão interessante acerca do par memória-lembrança: neste filme-mosaico, a narradora, em certos trechos, comenta, muito possivelmente, cartas enviadas por algum amigo próximo: “(...) ele me escreveu: eu passaria a vida a indagar sobre a função da lembrança, que não é o oposto do esquecimento, mas seu avesso. Nós não lembramos, recriamos a memória, como recriamos a história" (Cf. SEM sol, 1982).
} 
literariamente um $e u$ é, em última análise, lutar contra o esquecimento. Um $e u$ em versos diria que

[...] é preciso que minha voz tão estranha, minha voz que não gosto de ouvir, deixe de ser barulho que me trai, para tornar-se uma música que me transporte. E minha escrita, não uma mensagem que se perde no silêncio e só fala aos olhos, mas uma fala que faça vibrar os ouvidos do outro, e o obrigue a articular, em sua própria garganta, a minha vida (LEJEUNE, 2008, p. 89).

\section{Autobiografia e algo mais...}

Quando escrevo estou tentando descobrir o quem eu sou [...]

Maya Angelou

Não por outras razões, mas tenho até aqui tentado preservar a voz da autoria, para falar de Adélia Prado, pelo fato mesmo de ser quase incontestável o caráter autobiográfico [um euautor] que escorre de sua estética poética. Quando admito o elemento autobiográfico na literatura de Adélia Prado, estou também admitindo o lugar primeiro das múltiplas faces que a religião ocupa em sua vida e em sua poética. Tomo por empréstimo uma passagem de Maya Angelou ${ }^{4}$ ao falar do seu próprio trabalho estético: "Quando escrevo estou tentando descobrir o quem eu sou [...]". Portanto, o estabelecimento de um pacto autobiográfico entre a autora (Adélia Prado) e o seu testamento poético se circunscreve em um entrelugar que me permite adquirir um campo de percepção da experiência religiosa e, por conseguinte, da memória religiosa presente em seus escritos poéticos. A fala em primeira pessoa dos escritos adelianos se torna o principal rastro que aqui tento perseguir.

Os rastros autobiográficos articulam, em Adélia Prado, identidade feminina e memória religiosa. $^{5}$ Não se trata apenas da recuperação da autoridade da autoria, mas sim a da legitimação de uma (auto) interpretação da vida daquela que permite que sua autobiografia, promovida por um testemunho (ou seria ousado dizer um si mesmo?) se presentifique em seus textos. Falo aqui dos "vestígios" autobiográficos de que o texto adeliano é capaz de evocar. O que estou tentando dizer, em consonância com Philippe Lejeune, é que os versos

\footnotetext{
${ }^{4}$ Sobre a autora, site oficial disponível em http://mayaangelou.com.

${ }^{5}$ Como bem afirma Ángel Loureiro, em referência a Shari Benstock: "El la autobiografia, supuestamente, el sujeto se conhece a si mesmo a través del linguagem, el cual no es ni uma herramienta al serviço de la expresión del yo ni algo exterior al sujeito, sino el mismo sistema simbólico que constituye al sujeto y que es constituido por el sujeto que escribe. Pero este lenguaje está atravesado por trazas del inconsciente, y el sujeto, aunque parapetado en el lenguage, muestra sus divisiones internas [...]" (Cf. LOUREIRO, 1992, p. 39).
} 
autobiográficos procuram um caminho original para suas vozes. São, portanto, "tentativas de dicção" (LEJEUNE, 2008, p. 89). No caso de Adélia Prado, a via da religião é centro.

\section{Memória, experiência religiosa e testamento autobiográfico}

O espaço autobiográfico da poesia de Adélia Prado se abre com as seguintes condições estruturais: 1. A biográfica experiência religiosa (católica) da escritora e 2. A demarcação do feminino. É bom que se deixe claro: Adélia Prado jamais renunciou ao seu envolvimento com a fé católica. Em entrevista para os Cadernos de Literatura do Instituto Moreira Salles, a poetisa mineira reafirma a herança religiosa herdada de seus pais. Reproduzo integralmente a parte da entrevista na qual isso se evidencia:

CADERNOS DE LITERATURA BRASILEIRA: A morte de seus pais está intimamente ligada à sua produção poética. Além de tema, seus pais, embora bastante humildes - ele, ferroviário, ela, dona-de-casa -, foram responsáveis, de algum modo, por sua dedicação à literatura?

Adélia Prado: O papel determinante deles foi no sentido da experiência que eu tive na vida, principalmente na infância. É uma herança - a natureza psicológica, minha educação religiosa; aquilo tudo foi fundante. Para elaborar o que a gente chama de obra, eu busco tudo lá, meu tesouro está lá, na infância, com eles, uma experiência de natureza muito próxima das necessidades primeiras de todo mundo, por causa da quase penúria material. (grifos do autor)

[...]

CADERNOS: Algo ligado à chamada mineiridade?

Adélia Prado: Sim, isso é típico nosso, uma coisa bem, vamos dizer, Quaresma (aproveitando que a gente está na Quaresma). É um acento maior que existe na paixão e não na ressurreição de Cristo. Isso tem um apelo imagético, estético mesmo, muito forte: as procissões, a liturgia. É o nosso jeito de se relacionar com Deus. Nascemos para amar e servir a Deus e depois ser feliz com Ele no Céu - mas aqui isso tem um acento mesmo triste. [...]

CADERNOS: Portanto, neste caso, no seu caso, a experiência, a poesia, está a serviço da fé?

Adélia Prado: Eu não faço diferença. Para mim, experiência religiosa e experiência poética são uma coisa só.

$[\ldots]$

CADERNOS: A Sra. tem sido clara ao falar da relação de sua poesia com o divino, abreviada na fórmula precisa: esta voz é de Deus ou de Jonathan, mas a mão é minha.... Quais são, para Sra., os limites da poesia de Adélia Prado?

Adélia Prado: À medida que você cresce na experiência com Deus, o horizonte da poesia se alarga. Não tem limite para isso, não... Ou seja: você precisa ter novos poemas para falar daquela experiência

(CADERNOS DE LITERATURA BRASILEIRA, São Paulo: IMS, n. 9, 2000, p. 18). 
A religião em Adélia emerge dessa experiência profunda, que compõe indelevelmente sua biografia e seu testemunho poético. É na recordação que esse rastro autobiográfico vai tomando forma e se interligando à sua poesia. A educação religiosa e as experiências da infância são signos evidentes dessa interligação. Apresento um trecho de uma poesia intitulada Paixão, onde as raízes religiosas da escritora transparecem de modo evidente:

\section{Paixão}

De vez em quando Deus me tira a poesia.

Olho pedra, vejo pedra mesmo.

O mundo, cheio de departamentos, não é a bola bonita caminhando solta no espaço.

Eu fico feia, olhando espelhos com provocação, batendo a escova com força nos cabelos, sujeita à crença em presságios.

Viro péssima cristã.

(PRADO, 1991, p. 20). (Grifos do autor).

Esta voz que ressoa de sua poesia, ouvida por meio do verbo "viro", dita em primeira pessoa, é que denota a intenção de revelar o sentido de se sentir péssima cristã. Ser péssima cristã não é o avesso de ser uma cristã; é preciso se reconhecer no âmbito dessa tradição para dizer o quanto pode ou não se considerar uma boa ou má cristã.

\section{A poesia religiosa de Adélia Prado}

Quem entender a linguagem entende Deus.

Adélia Prado

Tive a oportunidade de entrevistar a poetisa Adélia Prado, em fevereiro de 2005, em Belo Horizonte. Um dos momentos mais interessantes da entrevista foi uma espontânea afirmação: penso todos os dias "em sexo, na morte e em Deus". 6

Por que enfatizar a renitência da tríade que a interpela todos os dias? Adélia deixa mais uma vez escapar um possível e silencioso pacto com sua literatura ao atestar que esta afirmação não pertence somente à escritora, mas também ao $e u$ que se revela em muitos momentos de suas obras poética e prosa. No poema "O modo poético", a denúncia transforma-se em evidência: “[...] é em sexo, morte e Deus, / que eu penso invariavelmente, todo dia" (PRADO, 1991, p. 79). Ao falar em sexo, morte e Deus, a escritora Adélia Prado nos remete a uma das faces da sua experiência religiosa. A experiência de Deus no espaço

\footnotetext{
${ }^{6}$ Fala extraída da entrevista concedida a mim, em 15 de fevereiro de 2005, Belo Horizonte.
} 
adeliano, - biográfico ou poético - exige um campo sensorial que permita o aparecimento da noção de opostos, entretanto, fundamentais para aquela quem tal experiência religiosa: finitude e desejo são os limiares que levam o eu adeliano da imanência à transcendência. A finitude, aqui representada pela morte, e o desejo, representado pela imagem erótica do sexo, que é experimentado através do corpo, tornam-se elementos complementares e quase que indissociáveis entre si no espaço poético de Adélia Prado. Pensando numa perspectiva um tanto inconoclasta, posso dizer, juntamente com José Carlos Barcellos, que "há [...] na poesia de Adélia Prado toda uma espiritualidade da encarnação, que se abre numa inequívoca valorização do cotidiano e do erotismo como espaço privilegiado de encontro com Deus" (BARCELLOS, 2003, p. 94). Representando e interpretando sua experiência católica, num itinerário teológico, o corpo se tornou um dos elementos mais evidentes da poesia adeliana. Tal expressão teológica torna-se patente no poema chamado "Deus não rejeita a obra de suas mãos":

É inútil o batismo para o corpo, o esforço da doutrina para ungir-nos, não coma, não beba, mantenha os quadris imóveis. Porque estes não são pecados do corpo.

À alma sim, a esta batizai, crismai, escreverei para ela a Imitação do Cristo.

O corpo não tem desvãos, só inocência e beleza, tanta que Deus imita e quer casar com sua Igreja e declara que os peitos de sua amada são como filhotes gêmeos da gazela. É inútil o batismo para o corpo. O que tem suas leis as cumprirá. Os olhos verão a Deus. (PRADO, 1991, p. 320).

Se o corpo é essencialmente santo, Adélia Prado não tarda a entender que toda experiência religiosa, inclusive a que escapa por esse eu, perpassa pelo seu corpo. Ao relacionar a sua criatividade estética à sua compreensão religiosa, a escritora mineira deixa bem clara a centralidade que o corpo tem em seus escritos. Então:

Poesia não é algo que eu crio com palavras; sento e falo: 'Agora com estas palavras vou criar isso ou aquilo'. As palavras me servem na medida em que me dão carne a uma experiência anterior. Eu só posso escrever porque existe essa experiência anterior [...] Para mim, é o corpo de cristo; ela [a 
palavra] é uma encarnação da divindade, é um experimento do divino. E o máximo desse experimento é um Deus que tem carne, que no caso é Jesus. É o máximo de poesia possível (CADERNOS DE LITERATURA, p. 24, grifo nosso).

Declara ainda, na entrevista realizada em Belo Horizonte, que se o cristianismo não pudesse ser entendido como uma religião que possui um Deus que também é corpo, ela não teria motivo nenhum para crer neste Deus e ser cristã. No poema A catecúmena, o eu adeliano me permite entrever, na sua possível teologia, que o elemento central de sua fé é a incorruptibilidade da carne, manifestando neste dado o seu desejo de viver e de crer:

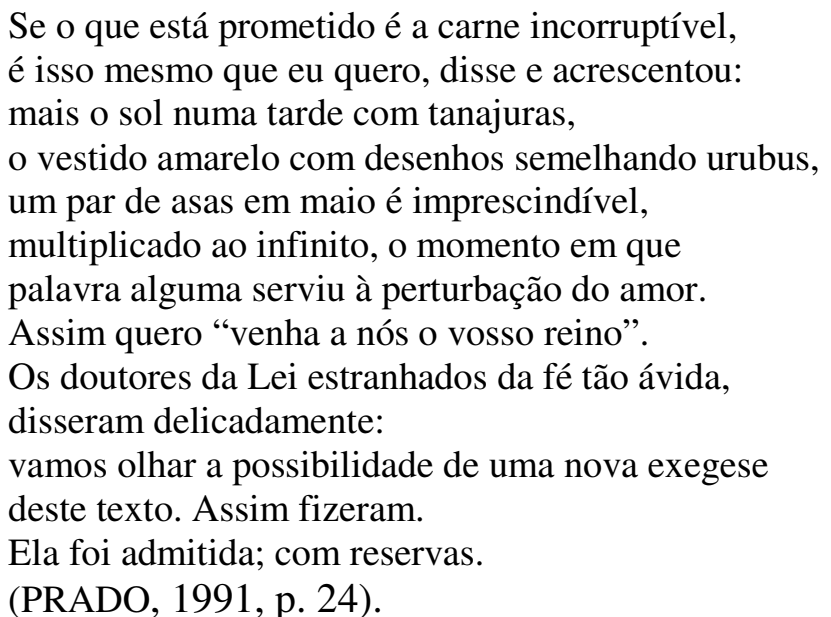

Antonio Magalhães entende que o eu adeliano presente no poema acima problematiza de forma crítica a teologia cristã corrente e aponta as dificuldades de as esferas magisteriais da fé se libertarem de seus preconceitos em relação a outras experiências, em função das verdades que defendem (MAGALHÃES, 2000, p. 196). Por entender que fazer teologia é sempre tornar as experiências religiosas possíveis e não condicioná-las, a teologia adeliana seria uma teologia que não depende de nenhum magistério eclesial, é autônoma.

Essa reinvenção da fé, ou seja, o modo sob o qual a sua literatura testemunha essa experiência religiosa, ao admitir o corpo e não a sua negação como elemento de trânsito para o sagrado, assume uma dinâmica potencializadora de uma espiritualidade imanente. A presença do maravilhoso, do numinoso, é representada pela vivência cristã (católica) transparecida no eu adeliano. Na esteira de Rudolf Otto - valendo-me da elasticidade de suas teorias sobre o sagrado - esse elemento perturbador, que é a presença do mistério, pode se reverter em algo que seduz, arrasta, arrebata e inebria (Cf. OTTO, 2005, p. 50). Otto identifica esse dado do sagrado como o elemento dionisíaco do numem. A este elemento cuja 
presença traz consigo uma sobrecarga dionisíaca, Otto chama de o fascinante. Esse eu adeliano demonstra-se fascinado com a presentificação do sagrado numa dimensão corpórea. Fascínio, no sentido de Rudolf Otto, e a beleza do corpo de Cristo deixam o eu adeliano prostrado. O poema Festa do corpo de Deus configura essa experiência quase extática desse eu atormentado pela força do sagrado corporeificado:

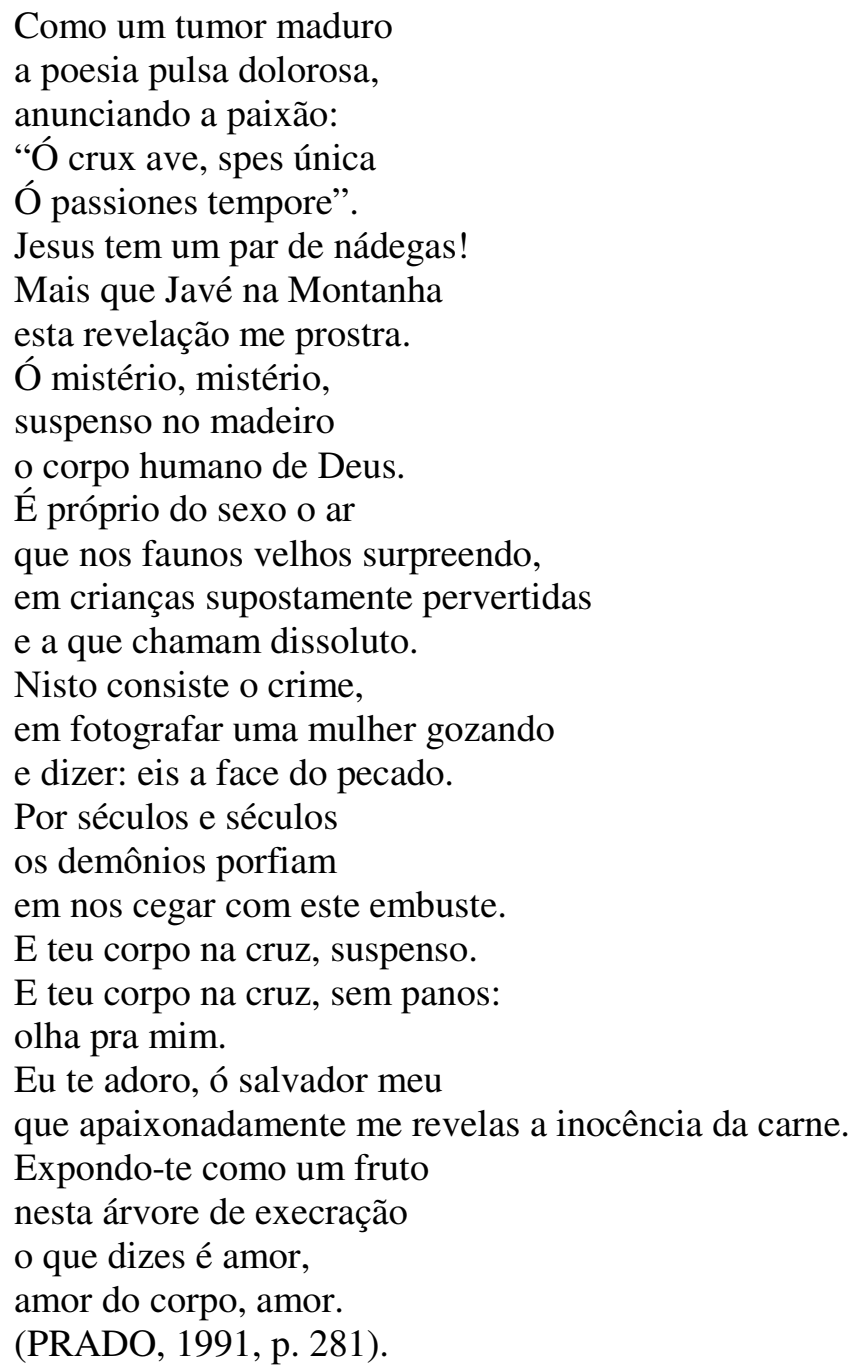

Mesmo que seja escândalo para a Igreja, Jesus tem, sim, um par de nádegas. Não nos esqueçamos de que o Jesus crucificado está quase nu. Estou certo de que a literatura é de fato o espaço onde tudo deve ser dito. Desconfio que o eu adeliano embarque num jogo cuja presença do sagrado evoca - na perspectiva de Otto - uma entrega através de seu apelo sedutor. Diante do fascinante nada se pode fazer. Eis aí uma autêntica prova da experiência profunda e radical, subsídios incontestes de uma literatura que testemunha tal experiência. A presença do fascinante é ao mesmo tempo terror e sedução. Esse jogo no qual afirmo existir 
uma expressão erótica e sedutora apresenta inicialmente certa resistência. $\mathrm{O}$ eu adeliano parece não querer se entregar ao apelo do fascinante. O poema "A filha da antiga lei" traz um eu mergulhando na inquietude provocada pelo fascínio do sagrado. É daqui, mas expressivamente, que vejo a emergência da representação de Deus enquanto incômodo. Isto é dito textualmente. $\mathrm{O}$ eu está à deriva, contudo intenta uma resistência diante daquilo que lhe fascina:

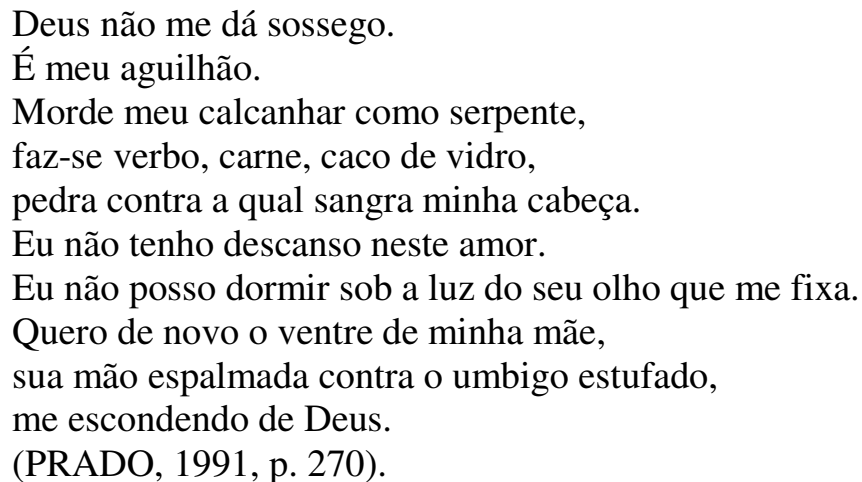

O sagrado só é sagrado porque está além das forças humanas. $\mathrm{O}$ eu adeliano ensaia a resistência, todavia a força do mistério é insuportável; diante dela não há alternativa; a entrega acontece. Em "O modo poético", a entrega é denunciada com ecos: "É na presença d'Ele que eu me dispo". Vamos ao poema:

Quando se passam alguns dias e o vento balança as placas numeradas na cabeceira das covas e bate um calor amarelo sobre inscrições e lápides, e quando se olha os retratos e se consegue dizer com límpida voz: ele gostava deste terno branco e quando se entra nas filas das viúvas, batendo papo e cabo de sombrinha,

é que a poeira misericordiosa recobriu coisa e dor, deu o retoque final.

Pode-se compreender de novo que esteve tudo certo, o tempo todo

e dizer sem soberba ou horror:

$e ́$ em sexo, morte e Deus que eu penso invariavelmente todo dia. É na presença d'Ele que eu me dispo e muito mais, d'Ele que não é pudico e não se ofende com as posições no amor. Quando tudo se recompõe, é saltitantes que nos vamos cuidar de horta e gaiola. A mala, a cuia, o chapéu enchem o nosso coração 
como uns amados brinquedos reencontrados.

Muito maior que a morte é a vida.

Um poeta sem orgulho é um homem de dores, muito mais de alegrias.

A seu cripto modo anuncia,

às vezes, quase inaudível

em delicado código:

'Cuidado entre as gretas do muro está nascendo a erva...'

Que a fonte da vida é Deus,

Há infinitas maneiras de entender.

(PRADO, 1991, p. 79) (Grifo meu).

Arrisco dizer, então, que em Adélia Prado a experiência religiosa, essa experiência que é ingovernável do ponto de vista das teologias mais rígidas, essa que por muitos é chamada de experiência com Deus, é, em síntese, uma experiência que incomoda. Deus é um incômodo! Sua força e seu significado residem nisto: em fazer com que as experiências dos humanos com Ele sejam sempre experiências marcantes; experiências que não são removíveis e, por isso, ganham um lugar seguro na ruptura do nosso silêncio.

\section{Referências bibliográficas:}

BARCELLOS, José Carlos. Mulher da Palavra. In: BINGEMER, Maria Clara Lucchetti; YUNES, Eliana (Orgs.). Mulheres de palavra. São Paulo: Edições Loyola, 2003.

BARTHES. Roland. O rumor da língua. 2. ed. São Paulo: Martins Fontes, 2004.

CADERNOS DE LITERATURA BRASILEIRA. São Paulo: IMS, n. 9, 2000.

DOCUMENTOS DO CONCÍLIO ECUMÊNICO VATICANO II. São Paulo: Paulus, 1997.

FOUCAULT, Michel. O que é um autor? 6. ed. Lisboa: Nova Veja, 2006.

KUSCHEL, Karl-Josef. Os escritores e as escrituras. São Paulo: Loyola, 1999.

LEJEUNE, Philippe. O pacto autobiográfico. Belo Horizonte: Editora da UFMG, 2008.

LOUREIRO, Ángel G. Direcciones en la teoría de la autobiografia. In: ROMERA, Jose et al. Escritura autobiográfica. Madrid: Visor Libros, 1992.

MAGALHÃES, Antonio. Deus no espelho das palavras. São Paulo: Paulinas, 2000.

NESTROVSKI, Arthur; SELIGMANN-SILVA, Márcio. Catástrofe e representação. São Paulo: Escuta, 2000.

OTTO, Rudolf. O sagrado. Lisboa: Edições 70, 2005. 
PLIMPTON, George. Escritoras e a arte da escrita. Rio de Janeiro: Gryfus, 2001.

PRADO, Adélia. Poesia reunida. São Paulo: Arx, 1991.

Prosa reunida. 2. ed. São Paulo: Siciliano, 1999.

PRADO BIEZMA, Javier del. Autobiografía y modernidad literaria. Cuenca: Universidad de Castilla-La Mancha, 1994.

QUEIROZ, Vera. $O$ vazio e o pleno: a poesia de Adélia Prado. Goiânia: Editora da UFG, 1994.

ROCHA, Clara. As máscaras de Narciso. Coimbra: Almedina, 1992.

SELIGMANN-SILVA, M. (Org.), História, memória, literatura: o testemunho na era das catástrofes. Campinas, SP: Editora da Unicamp, 2003.

SEM sol. Direção: Chris Marker. Produção: Anatole Dauman. Roteiro: Chris Marker. Narração: Florence Delay: Argos Films, 1982. DVD (100 min.).

TILLICH, P., Dinâmica da fé. 6. ed. São Leopoldo, RS: Sinodal, 2001.

En exprimant la foi: expérience religieuse, témoignage autobiographique et religieux dans la poésie de Adélia Prado

Resumé: Provient de la Constitution Pastorale Gaudium et Spes une préocupation qui tourne autour de la relation entre la «culture humaine et la formation chrétienne. » Le texte concilier met en relief que, certaines expressions culturelles, telles que « la litterature et les arts », sont très importantes pour la vie de l'Église », mais recconaît aussi que la relation entre la culture humaine et la tradiction religieuse chrétienne catholique n'est pas toujours harmonieuse et, donc, constitue un défi pour la diffusion de la théologie de l'église. On entrevoit, donc, la grande responsabilité des arts, car c'est à travers eux, de façon plus claire, que l'expresion de soi de l'être humain prend une forme, surtout, quand l'homme montre la recherche une compréhension de soi et la recherche de réponses à ses plus profonds dilemmes. En reconnaissant la responsabilité de surmonté les clivages qui séparent la culture humaine de la culture propagée par la tradition chrétienne, nous chercherons démontrer, dans cette communication, que l'expérience religieuse entrevue dans la litterature de la poète catholique Adélia Prado, évoquée par un moi-lirique emergent dans les versets de sa poésie, se rend à partir d'une dynamique de reconnaissance et d'éloignement, donc ambigus, de la confession religieuse de l'écrivain mineira. Deux axes, donc seront exploités dans cette communication: 1. l'influence, très claire, d'une tradition religieuse dans sa litterature et par la suite inférer le potentiel téologique; 2 . problématiser la présence d'un pacte autobiographique éveillé entre le moi-lirique féminin de la poésie adeliana et son témoignage biographique religieux de l'écrivain. 
Mots-clé: Litterature. Témoignage autobiographique. Expérience religieuse. 